\title{
A case of extreme alkalosis - the perfect combination of perpetuators
}

\author{
Patrícia Valério ${ }^{1}$, Hugo Ferreira ${ }^{2}$, Teresa Chuva ${ }^{2}$, Ana Paiva ${ }^{2}$, Inês Neves ${ }^{3}$, Filomena Faria ${ }^{3}$, José Maximino ${ }^{2}$ \\ ${ }^{1}$ Nephrology Department, Centro Hospitalar de Setúbal \\ 2 Nephrology Department, Instituto Português de Oncologia do Porto \\ ${ }^{3}$ Intensive Unit Care, Instituto Português de Oncologia do Porto, Portugal
}

\section{CASE PRESENTATION}

A 70-year-old Caucasian male, with an ECOG ${ }^{1}$ performance status of 1, was admitted in August 2019 for an elective surgery due to a stage II bladder urothelial carcinoma (pT2NOM0). The diagnosis was made one year ago and the patient had already undergone transurethral resection of bladder carcinoma six months earlier.

His past medical history consisted of hypertension, gout, smoking (50 pack-year), cystinuria with cystin coralliform nephrolithiasis and chronic kidney disease (CKD) G3A1 [basal serum creatinine (Cr) of 1.5 $\mathrm{mg} / \mathrm{dL}$ ] with a right kidney atrophy. He was medicated with amlodipine/ valsartan 5/160 mg id and alopurinol $300 \mathrm{mg}$ id.

A radical cystectomy with total right nephroureterectomy and cutaneous left ureterostomy was performed on august $23^{\text {rd }}$, without complication on the immediate postoperative period. He started oral diet in the first 24 hours. Diuresis was preserved, about 100 to $125 \mathrm{~mL} /$ hour.

Three days later the patient presented with abdominal distention and gastric stasis. He remained fasting, with gastric tube draining freely. Surgical team performed an exploratory laparotomy, with identification of an internal hernia of the small bowl, which was corrected.

In the postoperative period, nephrology collaboration was requested due to an acute kidney injury (AKI), with $\mathrm{Cr}$ of $3.39 \mathrm{mg} / \mathrm{dL}$ and urea of $89.5 \mathrm{mg} / \mathrm{dL}$. On our observation, the patient presented an auricular temperature of $37.4^{\circ}$, adequate peripheral oxygen saturation (99-100\%) with oxygen supply by face mask ( $\mathrm{FiO}_{2} 28 \%$ ) and a hypotensive profile (blood pressure of $114 / 66 \mathrm{~mm} \mathrm{Hg}$ ). The patient maintained passive drainage through nasogastric tube in the previous 3 days, around 3 to $3.5 \mathrm{~L} /$ day, without intestinal transit. Diuresis was preserved, about $60 \mathrm{~mL} /$ hour. He was prostrated and bradypneic, with mucosa severely dehydrated. The patient did not present any focal deficit and he answered simple questions only when vigorously stimulated. There was no alteration in pulmonary and cardiac auscultation. He was medicated with furosemide $20 \mathrm{mg}$ bid and still on his anti-hypertensive drugs. Empirical antibiotics (piperacillin/ tazobactam) were started the day before.

Arterial blood gas analysis presented a severe metabolic alkalosis, with $\mathrm{pH}$ of $7,63, \mathrm{PaO}_{2}$ of $90 \mathrm{~mm} \mathrm{Hg}, \mathrm{PaCO}_{2}$ of $99 \mathrm{~mm} \mathrm{Hg}$, bicarbonate of $104,1 \mathrm{mmol} / \mathrm{L}$, sodium of $142 \mathrm{mEq} / \mathrm{L}$, hypokalemia of $2.7 \mathrm{mEq} / \mathrm{L}$, low ionized calcium of $0.86 \mathrm{mmol} / \mathrm{L}$ and lactate of $1.9 \mathrm{mg} / \mathrm{dL}$. Blood work showed a Cr of 4,15 mg/dL, urea of $103,9 \mathrm{mg} / \mathrm{dL}$, hypernatremia of $147 \mathrm{mEq} / \mathrm{L}$, hypochloremia of $78 \mathrm{mEq} / \mathrm{L}$, hypokalemia of $3.2 \mathrm{mEq} / \mathrm{L}$, uric acid of $16.8 \mathrm{mg} / \mathrm{dL}$, albumin of $3.2 \mathrm{~g} / \mathrm{dL}$, total corrected calcium of $9.5 \mathrm{mg} / \mathrm{dL}$, elevated C-reactive protein of $38.38 \mathrm{mg} / \mathrm{dL}$ and procalcitonin of $1.31 \mathrm{ng} / \mathrm{mL}$. Urinalysis revealed an alkaline urine $(\mathrm{pH}$ 9.0), with $100 \mathrm{mg} / \mathrm{dL}$ of proteins and a urine microscopy with microhematuria (2-5 red blood cells/high power field). Table 1 shows the relevant laboratory findings during hospital admission and follow-up.

\section{QUESTIONS}

What is the cause of patient's metabolic alkalosis? How can we explain the electrolytic changes? How should we manage this patient?

\section{ANSWERS}

\section{What is the cause of patient's metabolic alkalosis?}

Metabolic alkalosis results from retention of alkali excess and it is characterized by an elevation of plasma bicarbonate concentration and, consequently, arterial blood $\mathrm{pH} .{ }^{1}$ Normally, a physiological response leads to hypoventilation with a secondary increase of $\mathrm{PaCO}_{2}{ }^{2}$

Plasma bicarbonate concentration can increase mainly due to excess hydrogen loss (renal or gastrointestinal), hydrogen movement into the cells and bicarbonate salts administration. ${ }^{3}$

The most common cause of metabolic alkalosis is hydrogen loss. In both renal or gastrointestinal losses, they are usually accompanied by the loss of chloride and potassium, resulting in hypochloremia and hypokalemia. ${ }^{1,3}$

Our patient maintained passive drainage through nasogastric tube in the previous 3 days, above $3 \mathrm{~L} /$ day, leading to a severe extrarenal loss of chloride and hydrogen, and a consequent bicarbonate increase. This was made evident by urinary spot chloride $(<20 \mathrm{mEq} / \mathrm{L})$, despite

${ }^{1}$ ECOG - Eastern Cooperative Oncology Group 


\section{Table I}

Relevant laboratory findings during hospitalization and follow-up.

\begin{tabular}{|c|c|c|c|c|c|c|c|c|c|c|c|}
\hline & & $22 / 08$ & $26 / 08$ & $28 / 08$ & $29 / 08$ & $30 / 08$ & $31 / 08$ & $02 / 09$ & $03 / 09$ & $18 / 09$ & $\begin{array}{c}20 / 12 \\
\text { (follow-up) }\end{array}$ \\
\hline \multirow{6}{*}{$\begin{array}{l}\text { Blood } \\
\text { work }\end{array}$} & $\mathrm{Hb}(\mathrm{g} / \mathrm{dL})$ & 12.7 & 10.8 & 10.1 & 10.7 & 7.2 & 8.1 & 9.4 & 10.1 & 8.7 & 11.7 \\
\hline & $\mathrm{Cr}(\mathrm{mg} / \mathrm{dL})$ & 1.48 & 1.79 & 3.39 & 4.15 & 3.77 & 3.67 & 2.78 & 2.25 & 1.58 & 1.57 \\
\hline & $\mathrm{Ur}(\mathrm{mg} / \mathrm{dL})$ & 70.3 & 46.8 & 89.5 & 103.9 & 99.7 & 94.3 & 69.1 & 56.5 & 34.8 & 58.0 \\
\hline & $\mathrm{K}^{+}(\mathrm{mEq} / \mathrm{L})$ & 4.2 & 3.8 & $3.6 \downarrow$ & $3.2 \downarrow$ & $3.4 \downarrow$ & $3.7 \downarrow$ & 4.6 & 4.4 & 5.0 & 4.6 \\
\hline & $\mathrm{Na}^{+}(\mathrm{mEq} / \mathrm{L})$ & 139 & 145 & $146 \uparrow$ & $147 \uparrow$ & $153 \uparrow$ & $153 \uparrow$ & $148 \uparrow$ & 142 & 136 & 137 \\
\hline & $\mathrm{Cl}^{-}(\mathrm{mEq} / \mathrm{L})$ & 107 & $94 \downarrow$ & $74 \downarrow$ & $78 \downarrow$ & $97 \downarrow$ & $99 \downarrow$ & $111 \uparrow$ & $111 \uparrow$ & 102 & 106 \\
\hline \multirow{9}{*}{$\begin{array}{c}\text { Spot } \\
\text { urine } \\
\text { analysis }\end{array}$} & $\mathrm{pH}$ & - & - & - & $9.0 \uparrow$ & - & - & - & - & - & 7.0 \\
\hline & Proteins (mg/dL) & - & - & - & 100 & - & - & - & - & - & 250 \\
\hline & $\mathrm{Hb}$ & - & - & - & Pos & - & - & - & - & - & Pos \\
\hline & Leuk esterase & - & - & - & $\mathrm{Neg}$ & - & - & - & - & - & Pos \\
\hline & Glucose, nitrites, ketones & - & - & - & $\mathrm{Neg}$ & - & - & - & - & - & $\mathrm{Neg}$ \\
\hline & Urine sediment & & & & $\begin{array}{c}2-5 \mathrm{RBC} / \\
\mathrm{HPF}\end{array}$ & & & & & & $\begin{array}{l}\text { 10-25 leuk/ HPF; } \\
\text { struvite crystals }\end{array}$ \\
\hline & $\mathrm{Na}^{+} \mathrm{U}(\mathrm{mEq} / \mathrm{L})$ & - & - & - & 133 & - & - & - & - & - & - \\
\hline & $\mathrm{K}^{+} \mathrm{U}(\mathrm{mEq} / \mathrm{L})$ & - & - & - & 44 & - & - & - & - & - & - \\
\hline & $\mathrm{Cl}^{-} \cup(\mathrm{mEq} / \mathrm{L})$ & - & - & - & 18 & - & - & - & - & - & - \\
\hline \multirow{3}{*}{$\begin{array}{c}\text { ABG } \\
\text { analysis }\end{array}$} & $\mathrm{pH}$ (arterial) & - & - & - & $7.63 \uparrow$ & $7.55 \uparrow$ & $7.54 \uparrow$ & 7.38 & 7.41 & - & \\
\hline & $\mathrm{HCO}^{3}-(\mathrm{mmol} / \mathrm{L})$ & - & - & - & $104.1 \uparrow$ & $50.4 \uparrow$ & $43 \uparrow$ & 25.4 & 21.8 & - & 24.5 (venous) \\
\hline & $\mathrm{PaCO}_{2}(\mathrm{~mm} \mathrm{Hg})$ & - & - & - & $99.0 \uparrow$ & $58.0 \uparrow$ & $54.0 \uparrow$ & 44.0 & 31.0 & - & \\
\hline
\end{tabular}

Abbreviations: ABG - arterial blood gas; $\mathrm{Cr}$ - creatinine; $\mathrm{Hb}$ - hemoglobin; HPF - high power filed; Leuk - leukocytes; Neg - negative; Pos - positive; RBC - red blood cells; Ur - urea; U - urine.

the concomitant use of diuretics. The loop diuretic may have played a role, not only by causing alkalosis by itself, but also by worsening the process through renal losses of chloride, potassium and volume depletion.

In individuals with adequate kidney function, kidneys respond to alkalosis with an increase in alkali excretion ${ }^{1}$ through 3 mechanisms: increase in filtered load, allowing a higher amount of bicarbonate to reach the distal nephron; chloride-dependent secretion of bicarbonate in the collecting duct ( $\beta$-intercalated cells), by pendrin $\mathrm{a} \mathrm{Cl}^{-} \mathrm{HCO}_{3}{ }^{-}$ exchanger); and down-regulation of hydrogen secretion in the collecting duct (inhibition of $\mathrm{K}^{+} / \mathrm{H}^{+}$-ATPase in the $\alpha$-intercalated cells). ${ }^{1,4}$ Table 2 shows metabolic alkalosis classification according to pathophysiology.

\section{Table II}

Metabolic alkalosis classification. Adapted from 1.

Alkali administration in setting of impaired alkali excretion, such as in kidney failure Secondary stimulation of ion transport in the collecting duct, with $\mathrm{Na}^{+}$uptake (ENaC principal cells) and $\mathrm{H}^{+}$and $\mathrm{K}^{+}$secretion $\left(\mathrm{K}^{+} / \mathrm{H}^{+}\right.$-ATPase $-\alpha$-intercalated cells): Extrarenal losses of $\mathrm{Cl}^{-}$;

Renal losses of $\mathrm{Cl}^{\text {: }}$ diuretics (thiazides or loop) and gene mutations that inactivate cotransporters $\mathrm{Na}^{+}-\mathrm{Cl}^{-}$(Gitelman or Bartter syndromes).

Primary stimulation of ion transport in the collecting duct with $\mathrm{Na}^{+}$uptake (ENaCprincipal cells) and $\mathrm{H}^{+}$and $\mathrm{K}^{+}$secretion $\left(\mathrm{K}^{+} / \mathrm{H}^{+}\right.$-ATPase $-\alpha$-intercalated cells): Mineralocorticoid excess;

Gene mutations that active $\mathrm{ENaC}$ or its signal pathway (Liddle syndrome...).
A sustained metabolic alkalosis only occurs when an additional factor impairs bicarbonate excretion or enhance its reabsorption, namely an impaired kidney function (in our patient, CKD with superimposed pre-renal AKI); hypochloremia (large amount of chloride rich gastric fluid losses); volume contraction (our patient was severely dehydrated from nasogastric tube, improper fluid administration and forced diuresis with furosemide); hypokalemia (fasting, secondary hyperaldosteronism due to volume contraction and furosemide) and increased sodium delivery to the distal nephron that led to hydrogen and potassium secretion (a loop diuretic effect, but less important in our patient). ${ }^{1,3}$

Our patient presented all these factors, that impaired the above-mentioned mechanisms, perpetuating alkalosis.

Hypoventilation and consequent $\mathrm{PaCO}_{2}$ elevation are a physiologic response to alkalemia, preventing life-incompatible $\mathrm{pH}$ elevations. For every $1.0 \mathrm{mM}$ increase in arterial bicarbonate concentration, $\mathrm{PaCO}_{2}$ should increase 0.5 to $0.7 \mathrm{~mm} \mathrm{Hg}{ }^{2}$ Mortality correlates with elevation of arterial $\mathrm{pH}$ : mortality rate could reach $45 \%$ in patients with arterial blood $\mathrm{pH}$ of 7.55 and $80 \%$ when $\mathrm{pH}$ is greater than 7.65. The prognosis is worse in patients with respiratory and metabolic alkalosis. ${ }^{5}$

The $\mathrm{PaCO}_{2}$ increase was lifesaving in our patient and it was appropriate to the degree of bicarbonate elevation (calculated respiratory compensation: $\mathrm{PaCO}_{2} 96 \mathrm{~mm} \mathrm{Hg}$ ). Such a dramatic increase was allowed by an appropriate arterial $\mathrm{PaO}_{2}$ maintained by external oxygen supply, despite bradypnea - hypoxia would have limited hypercapnia. 


\section{How can we explain the electrolytic changes?}

Our patient presented with severe hypochloremia, hypokalemia, hypernatremia and low ionized calcium.

The nasogastric tube was draining for several days, leading to a great loss of chloride and hydrogen rich fluid, provoking severe hypochloremia. Chloride depletion impairs chloride-dependent bicarbonate excretion and concomitant potassium depletion in distal nephron, through activation of ROMK channel (principal cells). These mechanisms lead to low urinary chloride and elevated urinary potassium, which can be measured in a spot urine. This secondary potassium depletion plays an essential role in alkalosis perpetuation, through maintenance of chloride depletion [downregulating $\mathrm{Na}^{+}-\mathrm{K}^{+}-$ $-2 \mathrm{Cl}^{-}$cotransporter (loop of Henle) and $\mathrm{Na}^{+}-\mathrm{Cl}^{-}$cotransporter (distal tubule)] and through loss of hydrogen (stimulating distal nephron $\mathrm{K}+$ / $\mathrm{H}+$-ATPase in the $\alpha$-intercalated cells) in order to maintain electroneutrality. Furthermore, potassium depletion induces renal ammonia production, allowing acid excretion and sustaining metabolic alkalosis. ${ }^{1,4}$ In our patient, chloride depletion, as well as volume depletion, was also exacerbated by furosemide. Further renal chloride losses can ensue when potassium depletion is severe and consequently much larger amounts of chloride are needed to correct alkalosis.

In this patient, hypernatremia is clearly hypovolemic, caused by severe dehydration due to nasogastric tube, poor fluid intake and forced diuresis. Hyperuricemia is also concordant with dehydration along with reduced glomerular filtration rate and furosemide use. ${ }^{6}$

The patient presented with hypocalcemia highlighted by low ionized calcium, despite normal corrected total calcium. This discrepancy is explained by alkalemia, which can alter the equilibrium of the albumin-calcium complex. PH elevation enhance their binding, leading to a lower ionized calcium (but not total calcium). When major shifts in $\mathrm{pH}$ are present, it is prudent to directly measure the ionized calcium level in order to determine the presence of hypocalcemia, its risk of complications and need for correction. However, it is expected that ionized calcium increases with alkalosis correction. ${ }^{7}$

\section{How should we manage this patient?}

The priority in this patient is to correct volume depletion with chloride rich fluids (such as $0,9 \% \mathrm{NaCl}$ ), along with potassium supplementation and prevention of continuing loss of chloride. ${ }^{3,8}$ Monitoring urinary chloride concentration can help guiding chloride replenishment and responsiveness of alkalosis to chloride administration. Calcium supplementation should be guided by possible occurrence of arrythmias or other complications, rather than trying to normalize it. ${ }^{9}$ Furosemide and hypotensive medication suspension is mandatory.

If nasogastric drainage must be continued, proper parenteral nutrition must be placed while correcting ongoing losses of fluids and electrolytes. Losses of chloride and hydrogen could be reduced with inhibition of gastric acid secretion. ${ }^{6}$ Prokinetics may have a role to treat ileus or even surgical correction of mechanical bowel obstruction, if present.
To proper care and monitorization of this life-threatening situation, the patient should be admitted to an intensive care unit (ICU). Due to severe AKI, dialysis with low bicarbonate dialysate may be indicated if the patient fails to improve with conservative measures or if life-threatening complications do not allow time for conservative correction of alkalosis. Hydrochloric acid infusion may have a role in severe cases in which dialysis is contra-indicated. $3,8,10$

Our patient was immediately admitted in ICU and he started on aggressive intravenous (IV) hydration with $\mathrm{NaCl} 0,9 \%$, along with IV potassium supplementation and parenteral nutrition. Offending drugs where discontinued and a proton pump inhibitor was started. The patient evolved with respiratory failure, needing invasive mechanical ventilation. Twelve hours after ICU admission, arterial blood gas showed a pH of 7.60, $\mathrm{PaCO}_{2}$ of $60.0 \mathrm{~mm} \mathrm{Hg}$ and bicarbonate of 58.9 $\mathrm{mmol} / \mathrm{L}$, while maintaining reasonable urinary output. On the next day, due to persistence of ileus a new exploratory laparotomy was performed, with detection of dilation of the small intestine, but without identification of a mechanical obstruction. He was started on prokinetics and the ileus resolved after few days. The patient had a progressive improvement with supportive measures, with no need for renal replacement therapy.

\section{FOLLOW-UP}

He was discharged on September $19^{\text {th }}$ completely recovered, with a $\mathrm{Cr}$ of $1.58 \mathrm{mg} / \mathrm{dL}$, and his anti-hypertensive medication was changed to captopril due to the etiology of the lithiasis.

Three months after discharge his functional status was excellent (ECOG 1) and renal function was stable.

\section{CONCLUSION}

This is an extreme case of metabolic alkalosis, where a myriad of contributors gathered in a perfect storm to achieve a bicarbonate concentration above $100 \mathrm{mmol} / \mathrm{L}$, thought to be incompatible with life and, to our knowledge, never reported in the literature. However, the $\mathrm{pH}$ value was maintained in life-compatible values by an extreme respiratory compensation which may have saved the patient before treatment initiation. Despite the severity of the alkalosis and AKI there was no need for dialysis to adequately treat this patient.

An approach correcting the cause and, at the same time, the perpetuators are the key factors to successfully treat a metabolic alkalosis.

Disclosure of potential conflicts of interest: none declared

\section{References}

1. Gennari FJ. Pathophysiology of metabolic alkalosis: a new classification based on the centrality of stimulated collecting duct ion transport. Am J Kidney Dis 2011;58(4):626-636.

2. Adrogue HJ, Gennari FJ, Galla JH, Madias NE. Assessing acid-base disorders. Kidney International 2009;76:1239-1247.

3. Galla JH. Metabolic alkalosis. J Am Soc Nephrol 2000;11:69-375. 
4. Hamm LL, Nakhoul N, Hering-Smith KS. Acid-base homeostasis. Clin J Am Soc Nephrol 2015;10:2232-2242.

5. Anderson LE, Henrich WL. Alkalemia-associated morbidity and mortality in medical and surgical patients. South Med J 1987;80(6):729-733.

6. Gennari FJ, Weise WJ. Acid-base disturbances in gastrointestinal disease. Clin J Am Soc Nephrol 2008;3:1861-1868.

7. Dickerson RN, Alexander KH, Minard G, Croce MA, Brown RO. Accuracy of methods to estimate ionized and "corrected" serum calcium concentrations in critically ill multiple trauma patients receiving specialized nutrition support. J Parenter Enteral Nutr 2004;28(3):133-141.

8. Gillion V et al. The patient with metabolic alkalosis. Acta Clin Belg 2019;74(1):34-40.

9. Cooper MS, Gittoes MS. Diagnosis and management of hypocalcaemia. BMJ 2008;336:1298-302.

10. Lisawat P, Gennari FJ. Approach to the hemodialysis patient with an abnormal serum bicarbonate concentration. Am J Kidney Dis 2014;64(1):151-155.

\section{Correspondence to:}

Patrícia Valério, MD

Hospital de São Bernardo - Serviço de Nefrologia, Rua Camilo Castelo Branco 175, 2910-549 Setúbal

E-mail: p.valerios89@gmail.com 